\title{
Software for Calculating the Non-Uniform Electric Field Causing Electrical Tree in Underground Cables
}

\author{
M. Talaat ${ }^{1, *}$, M. Magdy², A. Abd El-Baset ${ }^{2}$, M. Abo-Msallam³, A. Abdallah ${ }^{3}$, E. Mohamed ${ }^{2}$, A. Amer ${ }^{2}$, \\ M. El-Dallal ${ }^{2}$
}

\begin{abstract}
${ }^{1}$ Electrical Power \& Machines Department, Faculty of Engineering, Zagazig University, Zagazig, 44519, Egypt Postcode
${ }^{2}$ Higher Technological Institute Electrical \& Computer Department Tenth of Ramadan City

${ }^{3}$ Electrical Power \& Machines Department, Faculty of Engineering, Zagazig University
\end{abstract}

\begin{abstract}
In this paper new software is introduced to calculate the non-uniform electric field resulting from a protrusion of the earthing shield for underground cables. The problem is simulated by hyperbolic needle-to-plane electrodes which produce a very high non-uniform electric field causing the growth of electrical tree. The calculation of the electric field is achieved by charge simulation method combined by genetic algorithms for optimum location and values of the charges over the needle electrode. The charge over the needle electrode is simulated by a set of ring charges. The calculations are for different types of the dielectric materials of underground cables (PVC and XLPE). This software introduce an easy, economic and safety method to calculate the electrostatic field for underground cable. Also it presents a new method for predicting if this field will cause tree or not and then the program can classify that cable.
\end{abstract}

Keywords Non-uniform Electric Field, Charge Simulation Method, Electrical Tree, Underground Cable, Hyperbolic Needle to Plane Gap

\section{Introduction}

Electrical tree growth mechanisms have been modelled resorting to various approaches, from physical to purely phenomenological, which were investigated extensively during the last few decades and are still under study[1-4].

Considerable steps forward in the increase of knowledge on this phenomenon came from the possibility to carry out simultaneous PD and electroluminescence measurements[3].

A precursor model was presented in[1], which holds for initiation and growth of electrical trees in polymeric cable insulation. It assumes that local stress enhancements, which can take place in insulation due, for example, to contaminants or protrusions, cause inception of PD in adjacent small cavities once the electric field exceeds a threshold value. Electric charges thus penetrate into the insulation, giving rise to channels which form the electrical tree and grow with time until breakdown Experimental Setup[1].

The electric field plays an important role for electrical tree initiation, but this field produced from non-uniform edge which causes difficulty of this field calculation.

A simulation program with artificial intelligent, (genetic

* Corresponding author:

m_mtalaat@zu.edu.eg (M. Talaat)

Published online at http://journal.sapub.org/ijea

Copyright $(\underset{2}{2012}$ Scientific \& Academic Publishing. All Rights Reserved algorithms), software is required to calculate and simulate this field for fast and accurate detection of tree location and initiation.

\section{Electrical Field Calculation}

In the study of electrical breakdown of dielectric, and the design of high voltage devices a complete knowledge of electric field distribution is very important [5-10].

There are different methods available for the prediction of electric field in a given geometrical arrangement of conductors. These methods are classified into graphical, analogue, analytical and numerical.

The progress of electrical trees in an insulating system calls at first for accurate computation of the electrostatic field. This is obtained from Laplace's equation using charge simulation method CSM[1,6-8]. The needle electrode is simulated by a number of ring charges. The appropriate arrangement of these ring charges is achieved by genetic algorithms GAs[6,8].

At the needle tip the electric field must reach a value of 4 $\mathrm{MV} / \mathrm{cm}[1]$ for tree inception. A software program is introduced to calculate the electric field and indicate if it is lower than, equal or higher than the critical value $4 \mathrm{MV} / \mathrm{cm}$, so the tree prediction can be classify according to this value.

\subsection{Needle Simulation}

Figure 1 shows a hyperbolic needle-to-plane electrode 
system which is stressed by a voltage $V$ and embedded in solid insulation.

The needle has a tip radius $R$ and is located at spacing $S_{o}$ above the grounded plane.

The shape of the needle may be described by the hyperbolic function[11]:

$$
\frac{z^{2}}{S_{o}^{2}}-\frac{r^{2}}{S_{o} R}=1
$$

The distributed charge on the needle surface is simulated by a set of $\mathrm{n}$ ring charges arranged along the needle axis. The vector of unknown charges, $Q$ is computed from the matrix equation:

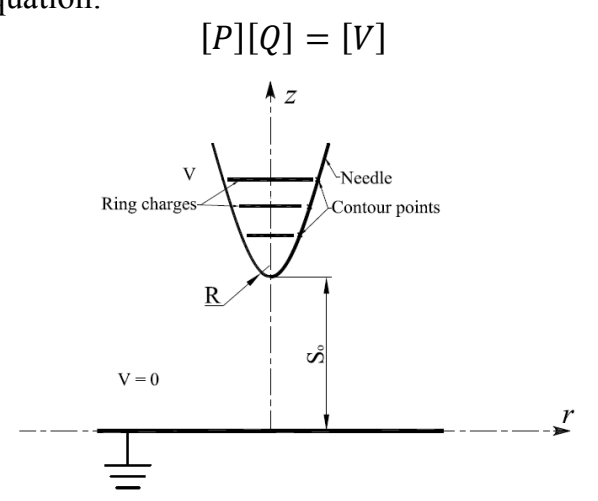

Figure 1. A hyperbolic needle-to-plane gap configuration

For a given charge distribution, the potential $\varnothing$ at an arbitrary point is a summation of the potentials resulting from the individual charges,

$$
\emptyset_{i}=\sum_{j=1}^{n} P_{i j} Q_{j} \quad i=1,2, \ldots \ldots . M
$$

where $M$ and $P_{i j}$ are the number of contour points, $(M=n)$ and potential coefficients, respectively.

The field stress is calculated by superposition of magni- tudes of various directional components. For example, in the Cartesian coordinate system, the net field $E_{i}$ at point $C_{i}$ is given by

$$
\begin{gathered}
E_{i}= \\
{\left[\sum_{j=1}^{n} \frac{\partial P_{i j}}{\partial x} Q_{j}\right] u_{x}+\left[\sum_{j=1}^{n} \frac{\partial P_{i j}}{\partial y} Q_{j}\right] u_{y}+\left[\sum_{j=1}^{n} \frac{\partial P_{i j}}{\partial z} Q_{j}\right] u_{z}} \\
E_{i}=\left[\sum_{j=1}^{n}\left(f_{i j}\right)_{x} Q_{j}\right] u_{x}+\left[\sum_{j=1}^{n}\left(f_{i j}\right)_{y} Q_{j}\right] u_{y}+ \\
{\left[\sum_{j=1}^{n}\left(f_{i j}\right)_{z} Q_{j}\right] u_{z}}
\end{gathered}
$$

where, $\left(f_{i j}\right)_{x},\left(f_{i j}\right)_{y},\left(f_{i j}\right)_{z}$ are the 'field intensity' or field coefficients and $u_{x}, u_{y}, u_{z}$ are unit vectors in the $x, y, z$ directions, respectively. In many cases, the electrostatic field between a system of conductors and an infinite plane with $\emptyset=0$ is of interest.

Electric field calculation in the dielectric medium in this software satisfies the Laplace's equation,

$$
\nabla^{2} V=0.0
$$

\section{Software Design}

Graphical user interface GUI under Matlab2010 has been used in the software design for electric field calculation. The required input data are the applied voltage of the cable, the insulation thickness, the needle tip radius, and the relative permittivity of the dielectric material. Figure 2 shows the screen for the software using in the electric field calculation.

This software is: easy to use, cheap, does not require experienced operator, gives a new classification of the underground cables depending on the electric field value produced from the sharp edge, which increase the price of high class cables.

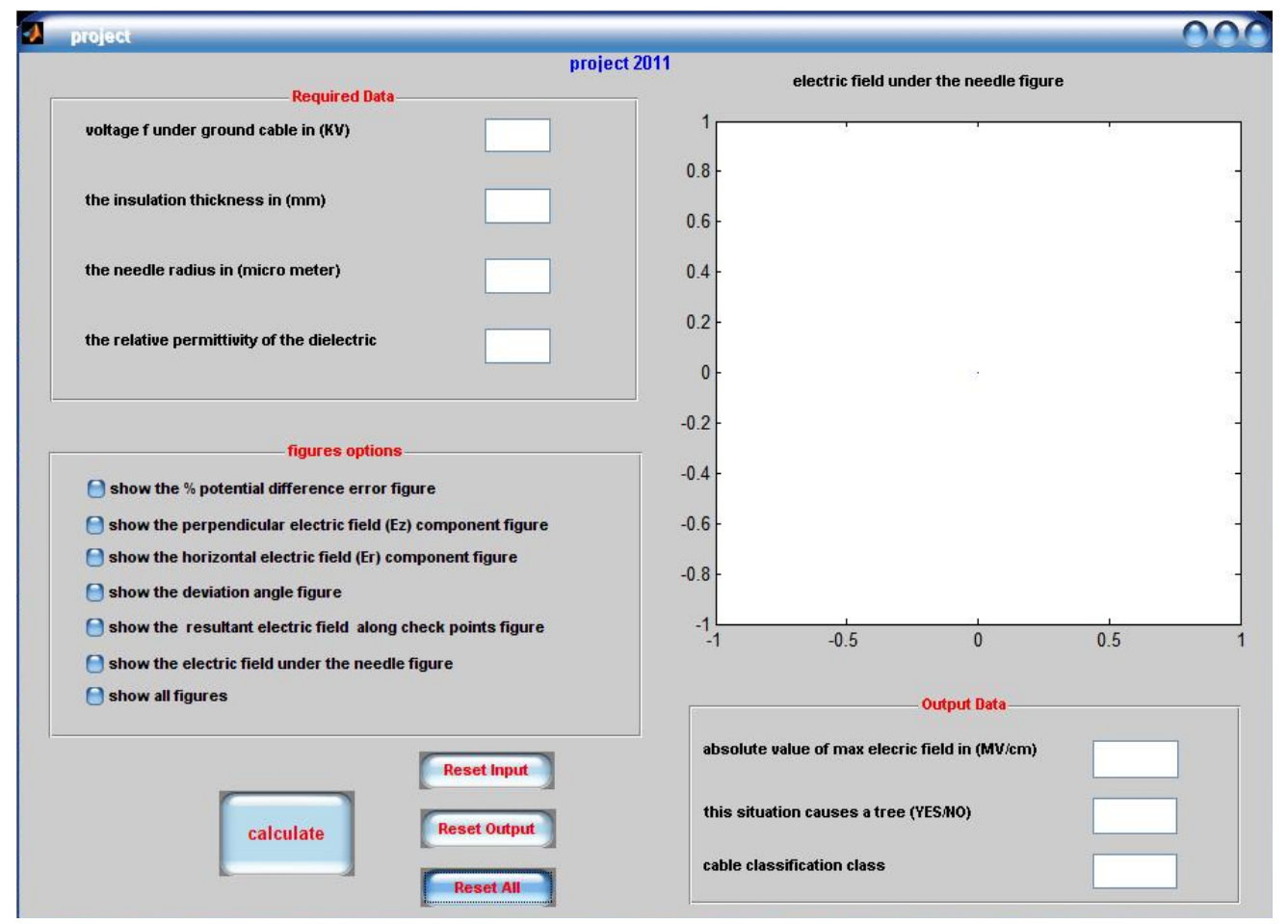

Figure 2. Software screen for electric field calculation 
Table 1. The output from software program for case one

\begin{tabular}{|c|c|c|c|c|c|c|c|c|c|c|}
\hline Radius in $(\mu \mathrm{m})$ & \multicolumn{2}{|c|}{$8 \mathrm{kV}$} & \multicolumn{2}{|c|}{$8.5 \mathrm{kV}$} & \multicolumn{2}{|c|}{$9 \mathrm{kV}$} & \multicolumn{2}{|c|}{$9.5 \mathrm{kV}$} & \multicolumn{2}{|c|}{$10 \mathrm{kV}$} \\
\hline & $\begin{array}{c}\text { Max field } \\
\text { in }(\mathrm{MV} / \mathrm{cm})\end{array}$ & $\begin{array}{l}\text { Tree } \\
(\mathrm{Y} / \mathrm{N})\end{array}$ & $\begin{array}{c}\text { Max field } \\
\text { in }(\mathrm{MV} / \mathrm{cm})\end{array}$ & $\begin{array}{l}\text { Tree } \\
(\mathrm{Y} / \mathrm{N})\end{array}$ & $\begin{array}{c}\text { Max field } \\
\text { in }(\mathrm{MV} / \mathrm{cm})\end{array}$ & $\begin{array}{c}\text { Tree } \\
(\mathrm{Y} / \mathrm{N})\end{array}$ & $\begin{array}{c}\text { Max field } \\
\text { in }(\mathrm{MV} / \mathrm{cm})\end{array}$ & $\begin{array}{l}\text { Tree } \\
(\mathrm{Y} / \mathrm{N})\end{array}$ & $\begin{array}{c}\text { Max field } \\
\text { in }(\mathrm{MV} / \mathrm{cm})\end{array}$ & $\begin{array}{l}\text { Tree } \\
(\mathrm{Y} / \mathrm{N})\end{array}$ \\
\hline 3 & 4.6152 & $\mathrm{Y}$ & 4.9039 & $\mathrm{Y}$ & 5.19205 & $\mathrm{Y}$ & 5.48049 & $\mathrm{Y}$ & 5.76894 & $\mathrm{Y}$ \\
\hline 4 & 3.5642 & $\mathrm{~N}$ & 3.78699 & $\mathrm{~N}$ & 4.00975 & $\mathrm{Y}$ & 4.23251 & $\mathrm{Y}$ & 4.45528 & Y \\
\hline 5 & 2.921 & $\mathrm{~N}$ & 3.10432 & $\mathrm{~N}$ & 3.28693 & $\mathrm{~N}$ & 3.46954 & $\mathrm{~N}$ & 3.65214 & $\mathrm{~N}$ \\
\hline 6 & 2.4863 & $\mathrm{~N}$ & 2.64166 & $\mathrm{~N}$ & 2.79705 & $\mathrm{~N}$ & 2.95244 & $\mathrm{~N}$ & 3.10783 & $\mathrm{~N}$ \\
\hline 7 & 2.1706 & $\mathrm{~N}$ & 2.3063 & $\mathrm{~N}$ & 2.44197 & $\mathrm{~N}$ & 2.57763 & $\mathrm{~N}$ & 2.7133 & $\mathrm{~N}$ \\
\hline 8 & 1.9308 & $\mathrm{~N}$ & 2.05145 & $\mathrm{~N}$ & 2.17212 & $\mathrm{~N}$ & 2.29279 & $\mathrm{~N}$ & 2.41347 & $\mathrm{~N}$ \\
\hline 9 & 1.742 & $\mathrm{~N}$ & 1.85083 & $\mathrm{~N}$ & 1.9597 & $\mathrm{~N}$ & 2.06857 & $\mathrm{~N}$ & 2.17745 & $\mathrm{~N}$ \\
\hline 10 & 1.589 & $\mathrm{~N}$ & 1.68856 & $\mathrm{~N}$ & 1.78789 & $\mathrm{~N}$ & 1.88721 & $\mathrm{~N}$ & 1.98654 & $\mathrm{~N}$ \\
\hline 11 & 1.463 & $\mathrm{~N}$ & 1.55443 & $\mathrm{~N}$ & 1.64587 & $\mathrm{~N}$ & 1.73731 & $\mathrm{~N}$ & 1.82875 & $\mathrm{~N}$ \\
\hline 12 & 1.3568 & $\mathrm{~N}$ & 1.4416 & $\mathrm{~N}$ & 1.5264 & $\mathrm{~N}$ & 1.6112 & $\mathrm{~N}$ & 1.696 & $\mathrm{~N}$ \\
\hline 13 & 1.3568 & $\mathrm{~N}$ & 1.34528 & $\mathrm{~N}$ & 1.42441 & $\mathrm{~N}$ & 1.50355 & $\mathrm{~N}$ & 1.58268 & $\mathrm{~N}$ \\
\hline 14 & 1.2661 & $\mathrm{~N}$ & 1.26203 & $\mathrm{~N}$ & 1.33626 & $\mathrm{~N}$ & 1.4105 & $\mathrm{~N}$ & 1.48474 & $\mathrm{~N}$ \\
\hline
\end{tabular}

Table 2. The output from software program for case two

\begin{tabular}{|c|c|c|c|c|c|c|c|c|c|c|}
\hline \multirow[t]{2}{*}{ Radius in $(\mu \mathrm{m})$} & \multicolumn{2}{|l|}{$8 \mathrm{kV}$} & \multicolumn{2}{|c|}{$8.5 \mathrm{kV}$} & \multicolumn{2}{|l|}{$9 \mathrm{kV}$} & \multicolumn{2}{|c|}{$9.5 \mathrm{kV}$} & \multicolumn{2}{|c|}{$10 \mathrm{kV}$} \\
\hline & $\begin{array}{l}\text { Max field } \\
\text { in }(\mathrm{MV} / \mathrm{cm})\end{array}$ & $\begin{array}{c}\text { Tree } \\
(\mathrm{Y} / \mathrm{N})\end{array}$ & $\begin{array}{c}\text { Max field } \\
\text { in }(\mathrm{MV} / \mathrm{cm})\end{array}$ & $\begin{array}{l}\text { Tree } \\
(\mathrm{Y} / \mathrm{N})\end{array}$ & $\begin{array}{l}\text { Max field } \\
\text { in }(\mathrm{MV} / \mathrm{cm})\end{array}$ & $\begin{array}{c}\text { Tree } \\
(\mathrm{Y} / \mathrm{N})\end{array}$ & $\begin{array}{l}\text { Max field } \\
\text { in }(\mathrm{MV} / \mathrm{cm})\end{array}$ & $\begin{array}{c}\text { Tree } \\
(\mathrm{Y} / \mathrm{N})\end{array}$ & $\begin{array}{c}\text { Max field } \\
\text { in }(\mathrm{MV} / \mathrm{cm})\end{array}$ & $\begin{array}{c}\text { Tree } \\
(\mathrm{Y} / \mathrm{N})\end{array}$ \\
\hline 3 & 4.69071 & $\mathrm{Y}$ & 4.98388 & $\mathrm{Y}$ & 5.27705 & $\mathrm{Y}$ & 5.57022 & $\mathrm{Y}$ & 5.86339 & $\mathrm{Y}$ \\
\hline 4 & 3.62754 & $\mathrm{~N}$ & 3.85426 & $\mathrm{~N}$ & 4.08099 & $\mathrm{Y}$ & 4.30771 & $\mathrm{Y}$ & 4.53443 & $\mathrm{Y}$ \\
\hline 5 & 2.97661 & $\mathrm{~N}$ & 3.16265 & $\mathrm{~N}$ & 3.34869 & $\mathrm{~N}$ & 3.53473 & $\mathrm{~N}$ & 3.72077 & $\mathrm{~N}$ \\
\hline 6 & 2.53498 & $\mathrm{~N}$ & 2.69342 & $\mathrm{~N}$ & 2.85186 & $\mathrm{~N}$ & 3.01029 & $\mathrm{~N}$ & 3.16873 & $\mathrm{~N}$ \\
\hline 7 & 2.21462 & $\mathrm{~N}$ & 2.35303 & $\mathrm{~N}$ & 2.49144 & $\mathrm{~N}$ & 2.62986 & $\mathrm{~N}$ & 2.76827 & $\mathrm{~N}$ \\
\hline 8 & 1.97098 & $\mathrm{~N}$ & 2.09417 & $\mathrm{~N}$ & 2.21736 & $\mathrm{~N}$ & 2.34054 & $\mathrm{~N}$ & 2.46373 & $\mathrm{~N}$ \\
\hline 9 & 1.7791 & $\mathrm{~N}$ & 1.89029 & $\mathrm{~N}$ & 2.00149 & $\mathrm{~N}$ & 2.11268 & $\mathrm{~N}$ & 2.22388 & $\mathrm{~N}$ \\
\hline 10 & 1.62382 & $\mathrm{~N}$ & 1.72531 & $\mathrm{~N}$ & 1.8268 & $\mathrm{~N}$ & 1.92829 & $\mathrm{~N}$ & 2.02978 & $\mathrm{~N}$ \\
\hline 11 & 1.49542 & $\mathrm{~N}$ & 1.58889 & $\mathrm{~N}$ & 1.68235 & $\mathrm{~N}$ & 1.77582 & $\mathrm{~N}$ & 1.86928 & $\mathrm{~N}$ \\
\hline 12 & 1.38737 & $\mathrm{~N}$ & 1.47408 & $\mathrm{~N}$ & 1.56079 & $\mathrm{~N}$ & 1.6475 & $\mathrm{~N}$ & 1.73421 & $\mathrm{~N}$ \\
\hline 13 & 1.2951 & $\mathrm{~N}$ & 1.37604 & $\mathrm{~N}$ & 1.45699 & $\mathrm{~N}$ & 1.53793 & $\mathrm{~N}$ & 1.61887 & $\mathrm{~N}$ \\
\hline 14 & 1.21533 & $\mathrm{~N}$ & 1.29128 & $\mathrm{~N}$ & 1.36724 & $\mathrm{~N}$ & 1.4432 & $\mathrm{~N}$ & 1.51916 & $\mathrm{~N}$ \\
\hline
\end{tabular}

\section{Results}

Case one: for PVC dielectric used in underground cable, Cable voltage (8-10) $\mathrm{kV}$, Cable insulation thickness $=5.2$ $\mathrm{mm}$, Cable insulation material (PVC) permittivity $=8$.

Table 1 represents the output from the software program for case one.

Case two: for XLPE dielectric used in underground cable, Cable voltage (8-10) $k V$, Cable insulation thickness $=3.4$ $\mathrm{mm}$, Cable insulation material permittivity $=2.3$.

Table 2 represents the output from the software program for case two.

\section{Conclusions}

The new software program presents a very simple method for calculation of a non-uniform electric field for hyperbolic needle-to-plane problem by using CSM combined with GAs and indicates the case for electrical tree formation in underground cable.

This software is easy and does not require experienced operator, also it gives a new classification of the cables and reduced the effort required to indicate the fault location of the cables. This classification depending on the electric field value produced from the sharp edge which can be indicating in the manufacturing process before using the cables.

The software can classify the high standard cables which increase its price.

\section{ACKNOWLEDGEMENTS}

The author thanks Prof. A. El-Zein and Prof. M. M. EI Bahy for their support and understanding of electrical tree mechanisms and simulation methods.

\section{REFERENCES}

[1] A. El-Zein, M. Talaat, and M. M. El Bahy. "A Numerical Model of Electrical Tree Growth in Solid Insulation" IEEE Transactions on Dielectrics and Electrical Insulation, Vol. 16, No. 6; pp. 1724-1734, December 2009.

[2] L. A. Dissado, S. J. Dood, J. V. Champion, P. I. Williams and J. M. Alison. "Propagation of Electrical Tree Structures in 
Solid Polymeric Insulation". IEEE Trans. Dielectric and Electrical Insulation, Vol. 4, No. 3, pp. 259-279, June 1997.

[3] L. A. Dissado. "Review Understanding Electrical Trees in Solids: from Experimental to Theory". IEEE Trans. On Dielectric and Electrical Insulation, Vol. 9, No. 4, pp. 483-497, August 2002.

[4] A. El-Zein, M. Talaat and M.M. El Bahy "A New Method to Predict the Electrical Tree Growth in Solid Insulation" Proceedings of the 16th International Symposium on High Voltage Engineering, (ISH 2009), paper D-15, pp. 1-6, 2009.

[5] A. El-Zein, M.M. El Bahy and M. Talaat "A Prediction Methodology of Electrical Tree Propagation in Solid Dielectrics" International Journal of Electrical Engineering, J. Elec. Eng. (2009) Vol. 9 / 2009 - No. 2, pp. 87-93, 2009.

[6] A. El-Zein, M.M. El Bahy and M. Talaat "A Simulation Model for Electrical Tree in Solid Insulation Using CSM Coupled with GAs" EEE Annual Report Conference on Electrical Insulation and Dielectric Phenomena CEIDP 2008, pp. 645-649, uebec, Canada October 26-29, 2008.

[7] M. Talaat "Electric Field Simulation along Silicone Rubber
Insulators Surface" Proceedings of the 17th International Symposium on High Voltage Engineering, (ISH 2011), paper A-22, pp. 1-6, 2011. Germany.

[8] M. Talaat "Charge Simulation Modeling for Calculation of Electrically Induced Human Body Currents" IEEE Annual Report Conference on Electrical Insulation and Dielectric Phenomen,a pp.644-647, CEIDP 2010, USA.

[9] H. Uehara and K. Kudo, "Directional Properties of Positive Impulse Tree Propagation in Oriented PET and PP Barrier Films Molded in EVA", IEEE Transactions on Dielectrics and Electrical Insulation Vol. 18, No. 1, pp. 162-167; 2011.

[10] B. Hennuy, Q. De Clerck, J. Marginet, D. Tenret, A. Francois and P. Leemans, "New Test Results With $3 \mathrm{kHz}$ Accelerated Growth of Water Trees in Medium Voltage XLPE Cables", $21^{\text {st }}$ International Conference on Electricity Distribution, CIRED, paper 679, 2011.

[11] W. L. Lama and C. F. Gallo, "Systematic Study of the Electrical Characteristics of the "Trichel" Current Pulses from Negative Needle to Plane Coronas”, J. Appl. Phys. Vol.45, pp. 103-113, 1974. 